\title{
Fostering modeling competencies: benefits of worked examples, problems to be solved, and fading procedures
}

\author{
Cornelia S. Große \\ FB3 Mathematics / Computer Science, University of Bremen, Bremen, Germany \\ For correspondence: cornelia.grosse@uni-bremen.de
}

\begin{abstract}
The application of mathematics to real-world problems is moving more and more in the focus of attention of mathematics education; however, many learners experience huge difficulties in relating "pure" mathematics to everyday contents. In order to solve "modeling problems", it is first necessary to find a transition from a real-world description to a mathematical model; second, intra-mathematical calculations have to be performed; and third, the result has to be interpreted with respect to the described real situation. In the present work, the effectivity of learning with worked examples and with fading procedures was tested experimentally. A design with 4 groups was implemented: "forward fading", "backward fading", "example-problem pairs", and "problem-example pairs". The results show that translation competencies were fostered best by way of example-problem pairs, whereas intramathematical skills were fostered most effectively by a backward fading procedure. Subjective assessments were especially positive when fading procedures or example-problem pairs were implemented.
\end{abstract}

Keywords: Mathematics learning, modeling problems, worked examples, fading

\section{Introduction}

There is a broad consensus that the ability to use mathematics flexibly in everyday situations is of major importance. Over the past years, mathematics education focused more and more on problems which are embedded in realistic contexts. However, it is often complained that students do not know how to translate real situations into mathematical notations and how to interpret results of mathematical operations. Still, with respect to a flexible application of mathematics in "out-of mathematical" situations, these are essential competencies.

Mathematical problems with realistic contexts.

Within the conceptual framework of the PISA study (OECD, 2003), "mathematical literacy" emphasizes the importance of applying mathematics to reality. "Modeling problems" are authentic, complex and open problems with close contact to real situations (e.g., Blum \& Borromeo Ferri, 2009). In the "scheme of mathematical modeling" (e.g., Blum, 1991), this connection between mathematics and reality becomes visible. This model proposes a cyclic process of five steps: First, a real situation has to be translated in a "real model". In the second step, this real model has to be translated into mathematics, resulting in a "mathematical model". In the third step, mathematical operations are applied and lead to "mathematical results". In the fourth step, "real results" are obtained by interpreting the mathematical results with respect to the real situation. In the last step it is tested whether this solution is satisfactory with respect to the real problem situation. If not, each step of the cycle has to be performed again.

Modeling problems do not necessarily contain all relevant information; the learners may have to estimate or otherwise gain missing information. Irrelevant information may be given, and the learners may have to choose an appropriate interpretation (see also Palm, 2008). It is widely agreed that mathematics education should emphasize applying and modeling (e.g., Blum, 1991; Borromeo Ferri, 
2009). The importance of real contexts in order to foster comprehension and transfer is also emphasized by various theories. In particular, constructivist approaches point out the importance of situated learning in concrete contexts (for an overview see Reinmann \& Mandl, 2006). Following this approach, learning processes should be connected with authentic problems, so that knowledge is acquired from the view of application. Authentic examples accentuate the relevance of the learning contents which is supposed to enhance learning motivation (e.g., Visser \& Keller, 1990); thus, also in view of learning motivation, addressing modeling problems in mathematics education is supposed to be beneficial.

However, these positive aspects connected to modeling problems are only one side of the coin. The other side of the coin is the high level of requirements associated with solving modeling problems; translation processes pose high demands on the learners. Learners often do not consider reality when working on mathematics problems (e.g., Greer, 1997; Reusser \& Stebler, 1997; Verschaffel et al., 1994, 1997, 1999). Often, children do not follow the above described "scheme of mathematical modeling", but take a shortcut by just selecting a mathematical operation, inserting values from the problem formulation, performing the calculation, and indicating the result - typically without checking for plausibility (Greer, 1997).

Existing approaches to foster modeling competencies.

While there is only a limited number of studies dealing with the acquisition of modeling skills, improving word problem solving is addressed by a variety of studies. In contrast to modeling problems, word problems are less complex; however, transition processes between a verbal description and a mathematical notation are necessary nevertheless. It is a prerequisite to fully understand the information given in the problem formulation, and it can be assumed that a large part of the learners' difficulties is rooted in underlying reading deficiencies. This assumption is substantiated by studies revealing a close relationship between reading comprehension and performance on word or modeling problems (e.g., Vilenius-Tuohimaa et al., 2008; Leiss et al., 2010). Considering reality when working on mathematics problems seems to be difficult for students, and in order to stimulate more critical reflections learners were warned that (some) problems were more difficult than to be expected at first glance. However, improvements with respect to realistic considerations were limited; in contrast, strengthening the authenticity of the problem situations fostered realistic considerations (for an overview, see Verschaffel et al., 2010). Several studies assessed the effects of schema-based instruction on word problem solving; overall, positive effects of teaching learners to recognize problem types and matching solution methods were found (for an overview, see Powell, 2011). Positive results were also obtained for trainings focusing on metacognitive strategies (e.g., de Kock \& Harskamp, 2014; Mevarech et al., 2010).

With respect to modeling skills, Galbraith and Clatworthy (1990) showed that it is possible to acquire mathematical modeling skills; however, the validity of this study is limited as no control group was implemented. Zöttl et al. (2010) examined the effectivity of a variety of measures, as for example heuristic worked examples, prompts for self-explanations, self-tests, and the possibility to write a learning journal. In sum, this learning environment fostered learning outcomes to a great extent; however, it cannot be concluded which particular measure(s) actually caused the improvement. Schukajlow and Blum (2011; see also Blum \& Borromeo Ferri, 2009) showed that cognitively activating education focusing on individual work fostered modeling competencies.

In sum, it can be concluded that these existing studies showed that it is indeed possible to foster modeling competencies. However, one very prominent and effective learning method was not implemented in "pure" form: Learning with worked examples (for an overview, see Atkinson et al., 2000). It is a particular advantage of this learning method that the learners do not have to meet all the demands of a problem at the same time, but that they can be confronted with a complex problem anyway. In the context of modeling problems, this allows to address real problems without the risk of asking too much of the learners. 
Learning with worked examples.

In well-structured domains such as mathematics, worked examples are commonly used. A wide variety of studies documents the effectivity of presenting problems along with corresponding solutions (e.g., Cooper \& Sweller, 1987; Sweller \& Cooper, 1985), and a large number of effective example characteristics and learners' activities have been identified (for an overview see Atkinson et al. 2000; for a comprehensive theory of example-based learning integrating theoretical assumptions and findings from observational learning and analogical reasoning see Renkl, 2014). The advantages of learning with worked examples are often explained referring to the cognitive load theory (e.g., Paas et al., 2003); it is argued that worked examples reduce extraneous cognitive load by reducing element interactivity (Sweller, 2010) and, thus, make cognitive resources available for constructing and automating a cognitive schema (see also van Gog et al., 2004, 2006, 2008).

However, the learner does not get feedback with respect to the own learning progress, and lacking meta-knowledge of how to learn from worked examples may lead to a merely superficial processing of the examples. Further, in the end, learners are supposed to be able to solve problems on their own, so it makes sense to abandon the "complete" worked examples at some point in the learning process. Basically, there are two possibilities how that could be accomplished. First, it is possible to integrate problems to be solved in the "worked examples lessons". In many studies, pairs of examples and problems to be solved were used (e.g., Cooper \& Sweller, 1987; Sweller \& Cooper, 1985); accordingly, a close link between examples and problems enhances learning (Trafton \& Reiser, 1993).

Second, it is possible to use "incomplete examples" which do not display all solution steps. Several studies show the benefits of using incomplete examples (e.g., Stark, 1999; van Merriënboer, 1990). "Fading" means that gradually more and more solution steps are omitted in worked examples until only the problem formulation is left (Atkinson et al., 2003; Renkl et al., 2002, 2004); consequently, the requirements increase only gradually, and the learners are not overwhelmed on their way to learn solving problems on their own. In several experiments it could be shown that fading is more effective than learning with example-problem pairs (e.g., Atkinson et al., 2003; Renkl et al., 2002, 2004).

Fading out solution steps can be realized in two ways: Following a "forward rationale" means that the solution steps are omitted from the beginning of the solution, thus, the learners start with solving the first solution step on their own. In contrast, following a "backward rationale" means that solution steps are omitted from the end of the solution, which means that the learners start with solving the last step on their own. Results of Renkl et al. (2002) indicate that a backward rationale is more effective than a forward rationale. From the point of view of the cognitive load theory, the backward rationale reduces the probability of a presented solution step being redundant, and thus increases the probability of supporting learning effectively (see also Renkl et al., 2004). In a study of Reisslein et al. (2006), the effectivity of problem-example pairs, example-problem pairs, and backward fading was compared in the context of parallel and series electrical circuits. No significant differences with respect to near and far transfer performance were found; however, for learners with low prior knowledge, example-problem pairs were especially beneficial. In a more recent study, Kissane et al. (2008) compared a fading condition with an example-problem pairs condition and a problem solving condition, and they found a superiority of fading with respect to delayed and transfer posttest performance; however, it has to be noted that the sample sizes were rather small. In a study of Moreno et al. (2009) the participants in a forward fading and in a problem solving condition outperformed the participants in a backward fading condition significantly with respect to near transfer, but not for far transfer.

So far, the focus of the present article was on objective learning outcomes. However, this is just one side of the coin. Not only from a scientific point of view, but also with regard to "real" mathematics education, it is also of major importance whether the learners like the learning materials and whether they are confident that they will be able to work with them successfully.

Fostering positive attitudes toward modeling problems.

If the requirements for learners are reduced, this fosters self-efficacy: If learners are able to meet the demands, their confidence of being able to keep up in the future will rise (Bandura, 1977). Self- 
efficacy significantly influences motivation and achievement (for an overview, see Bandura \& Locke, 2003). Thus, it can be assumed that initially lowering the requirements connected with modeling problems and enabling the learners to meet those requirements can lower the subjectively perceived difficulty of the problems and can enhance the assuredness of the learners that they would be able to solve the problems. Accordingly, Große (2014a) showed that focused story problems were substantially more appreciated by the learners than detailed story problems.

\section{Research questions}

The intention of the present experiment was to test whether a fading procedure can foster modeling competencies more effectively than pairs of worked examples and problems to be solved. In addition to objective learning outcomes, subjective measures were assessed as well. The following research questions were addressed:

1. Is it more effective to use a fading procedure compared to alternately presenting worked examples and problems to be solved?

Hypothesis 1: A fading procedure has more positive outcomes than alternately presenting worked examples and problems to be solved, both with respect to objective learning outcomes and with respect to subjective measures.

2. When implementing a fading procedure, is a "backward" procedure more effective than a "forward" procedure?

Neither of the above mentioned "fading" studies used modeling problems as learning domain, so the question remains open whether the effectivity of both fading procedures differs in this context. Especially, a substantial part of the mentioned studies used problems in the domain of probability, where the difficulty of each single solution step can be assumed to be similar or at least comparable. In contrast, the here used modeling problems require a wide range of competencies. Following a suggestion of Renkl et al. (2002), it might be favorable to fade out the easiest step first in order to reduce problem solving requirements and free cognitive resources for effective learning activities. In the present context, it can be assumed that the first step - the translation process from a real problem to a mathematical notation - is particularly difficult for learners. Verschaffel et al. (2010) showed that considerations with respect to real aspects are especially rare when they would be important at the beginning of a problem (i.e., in the translation process from reality to mathematics). It seems to be easier for learners to keep reality in mind at the end of a solution process. This supports the suggestion that a backward fading rationale might be more effective with respect to modeling problems, as the especially difficult step from reality to mathematics is then provided longer in a worked out manner.

Hypothesis 2: "Backward fading" has more positive outcomes than "forward fading", both with respect to objective learning outcomes and with respect to subjective measures.

3. When combining pairs of worked examples and problems to be solved, is it more effective to start the sequences with worked examples or with problems to be solved?

While starting with a problem shows the learners clearly what they do or do not know, starting with an example gives them a clear and unambiguous idea of what they are expected to do. Thus, the following hypothesis is formulated non-directionally.

Hypothesis 3: Starting with worked examples differs from starting with problems to be solved with respect to objective and subjective outcome measures. 


\section{Methods}

Sample and design.

The participants of this study were $n=1438^{\text {th }}$ grade students (mean age: 13.56 years, $S D=.61 ; 73$ female, 70 male) of a German "Gymnasium" (secondary school). At the time of the experiment, the participants had just learned how to solve systems of equations. The study took place in the context of regular mathematics courses. In order to address the research questions, a design with four groups was implemented; the participants were randomly assigned to "forward fading" ( $n=37)$, "backward fading" ( $n=35)$, "example-problem pairs" $(n=35)$, and "problem-example pairs" $(n=36)$ (within each class, all four experimental conditions were represented approximately equally).

\section{Materials.}

Modeling problems which can be solved by means of linear equation systems served as learning domain. According to Zöttl et al. (2010) $8^{\text {th }}$ graders often have only little experience with modeling problems; however, solving linear equation systems is part of their regular mathematics courses. Thus, combining those two - modeling problems using linear equation systems - seemed to be appropriate. The modeling problems used in the present study did not provide all necessary information in order to calculate an exact result, thus, the learners were required to estimate information.

The learning phase consisted of four problems. Depending on the experimental condition, they were presented as worked examples, partially worked examples, or problems to be solved. Across all experimental conditions, half of the solution steps were presented in a worked out format, and the other half of the steps had to be solved by the learners.

In the groups with fading, the following fading procedure was implemented: The first problem was presented with a complete worked solution. The second problem was presented with a solution whereby one step was missing. For the third problem, the solution was missing two steps. The last problem had to be solved completely by the learners. In the "forward fading" condition, the steps were faded out from the beginning, and in the "backward fading" condition, the steps were faded out from the end of the solution. In the other two groups, complete worked examples and problems to be solved were presented alternately. In the "example-problem pairs" condition, a worked example was presented first, followed by a problem to be solved, whereas in the "problem-example pairs" condition, the sequence started with a problem to be solved, followed by a worked example. Table 1 illustrates this procedure, and Table 2 gives an example for one of the problems provided in the learning phase. The learners were allowed to go back and forth between these four problems.

Table 1: Sequence of (faded) worked examples and problems to be solved.

\begin{tabular}{|c|c|c|c|c|}
\hline & Forward fading & Backward fading & $\begin{array}{l}\text { Example-problem- } \\
\text { pairs }\end{array}$ & $\begin{array}{c}\text { Problem-example- } \\
\text { pairs }\end{array}$ \\
\hline Problem 1 & $\begin{array}{l}\text { Complete worked } \\
\text { example (all } 3 \text { steps } \\
\text { presented) }\end{array}$ & $\begin{array}{l}\text { Complete worked } \\
\text { example (all } 3 \text { steps } \\
\text { presented) }\end{array}$ & $\begin{array}{l}\text { Complete worked } \\
\text { example (all } 3 \text { steps } \\
\text { presented) }\end{array}$ & $\begin{array}{l}\text { Problem to be solved } \\
\text { (no steps presented) }\end{array}$ \\
\hline Problem 2 & $\begin{array}{l}\text { Step } 1 \text { to be solved } \\
\text { Steps } 2 \text { and } 3 \\
\text { presented }\end{array}$ & $\begin{array}{l}\text { Steps } 1 \text { and } 2 \\
\text { presented Step } 3 \text { to be } \\
\text { solved }\end{array}$ & $\begin{array}{l}\text { Problem to be solved } \\
\text { (no steps presented) }\end{array}$ & $\begin{array}{l}\text { Complete worked } \\
\text { example (all } 3 \text { steps } \\
\text { presented) }\end{array}$ \\
\hline Problem 3 & $\begin{array}{l}\text { Steps } 1 \text { and } 2 \text { to be } \\
\text { solved } \\
\text { Step } 3 \text { presented }\end{array}$ & $\begin{array}{l}\text { Step } 1 \text { presented } \\
\text { Steps } 2 \text { and } 3 \text { to be } \\
\text { solved }\end{array}$ & $\begin{array}{l}\text { Complete worked } \\
\text { example (all } 3 \text { steps } \\
\text { presented) }\end{array}$ & $\begin{array}{l}\text { Problem to be solved } \\
\text { (no steps presented) }\end{array}$ \\
\hline Problem 4 & $\begin{array}{l}\text { Problem to be solved } \\
\text { (no steps presented) }\end{array}$ & $\begin{array}{l}\text { Problem to be solved } \\
\text { (no steps presented) }\end{array}$ & $\begin{array}{l}\text { Problem to be solved } \\
\text { (no steps presented) }\end{array}$ & $\begin{array}{l}\text { Complete worked } \\
\text { example (all } 3 \text { steps } \\
\text { presented) }\end{array}$ \\
\hline
\end{tabular}

Note: "Step 1" refers to the translation from reality into mathematics, "step 2" refers to the intra-mathematical part, and "step 3" refers to the interpretation of the mathematical result with respect to the real problem. 
Table 2: Example problems used in the learning phase (second example; translated from German).

Problem In the fall break, you want to go for a bicycle tour with four friends. As you don't have much money you formulation decide to spend the nights in a tent. Unfortunately, the weather forecast is not very encouraging: It will be (same for all around 15 degrees and rain a lot. There was no way you want to cancel the tour, so you decide to buy rain conditions) casings for your bike helmets so that your hair remains dry and you can happily leave the hair dryer at home. And you want to buy thick inflatable mattresses which will float if necessary, so that you can sleep late comfortably even if the tent is leaky.

For $€ 26.90$ you buy two inflatable mattresses, three rain casings for bike helmets, and a bar of chocolate because lunch tasted awful (and you have to eat something). Denise buys two inflatable mattresses and two rain casings (for $€ 24.00$ ) - and indeed the same as you. Now there is an inflatable mattress and a rain casing for everyone, as Anton already possesses an inflatable mattress. Now you just have to find out the prices of an inflatable mattress and of a rain casing. You should have retained the receipt! But never mind, you can calculate the prices if you estimate the price for the bar of chocolate.

Forward fading Please find the first solution steps on your own:

[free space for writing down]

From here on, the problem is already solved. Please try to understand the solution:

$$
\begin{array}{|l}
2 x+3 y+0.9=26.9 \\
2 x+2 y
\end{array}
$$

If you subtract $3 y$ and 0.9 from both sides in equation (1), you get:

$$
2 \mathrm{x}=26-3 \mathrm{y} \Rightarrow \mathrm{x}=13-1.5 \mathrm{y}
$$

If you insert this in equation (2), you get:

$$
2(13-1,5 y)+2 y=24 \Rightarrow 26-3 y+2 y=24 \Rightarrow y=2
$$

If you insert this in the equation which was solved for $x$, you get:

$$
x=13-1,5 \cdot 2=13-3=10
$$

Answer: An inflatable mattress costs around $€ 10.00$, and a rain casing for a bike helmet costs around $€ 2.00$.

Backward In the following, the beginning of the solution is presented. Please try to understand these steps:

fading Let $\mathrm{x}$ be the price for an inflatable mattress (in $€$ ) and $\mathrm{y}$ the price for a rain casing (in $€$ ). Let us assume that the bar of chocolate costs $€ 0.90$.

$$
\begin{array}{|l}
2 x+3 y+0.9=26.9 \\
2 x+2 y=24
\end{array}
$$

If you subtract $3 y$ and 0.9 from both sides in equation (1), you get:

$$
2 \mathrm{x}=26-3 \mathrm{y} \Rightarrow \mathrm{x}=13-1.5 \mathrm{y}
$$

If you insert this in equation (2), you get:

$$
2(13-1,5 y)+2 y=24 \Rightarrow 26-3 y+2 y=24 \Rightarrow y=2
$$

If you insert this in the equation which was solved for $x$, you get:

$$
x=13-1,5 \cdot 2=13-3=10
$$

Please find an answer:

[free space for writing down]

\begin{tabular}{ll}
\hline $\begin{array}{l}\text { Example- } \\
\text { problem-pairs }\end{array}$ & $\begin{array}{l}\text { Please find the solution on your own: } \\
\text { [free space for writing down] }\end{array}$ \\
\hline $\begin{array}{l}\text { Problem- } \\
\text { example-pairs }\end{array}$ & $\begin{array}{l}\text { This problem is already solved completely. Please try to understand the solution: } \\
\text { Let } \mathrm{x} \text { be the price for an inflatable mattress (in } € \text { ) and } \mathrm{y} \text { the price for a rain casing (in } € \text { ). Let us assume that the }\end{array}$
\end{tabular}

bar of chocolate costs $€ 0.90$.

$$
\begin{aligned}
& 2 x+3 y+0.9=26.9 \\
& 2 x+2 y=24
\end{aligned}
$$

If you subtract $3 y$ and 0.9 from both sides in equation (1), you get:

$$
2 \mathrm{x}=26-3 \mathrm{y} \Rightarrow \mathrm{x}=13-1.5 \mathrm{y}
$$

If you insert this in equation (2), you get:

$$
2(13-1,5 y)+2 y=24 \Rightarrow 26-3 y+2 y=24 \Rightarrow y=2
$$

If you insert this in the equation which was solved for $x$, you get:

$$
x=13-1,5 \cdot 2=13-3=10
$$

Answer: An inflatable mattress costs around $€ 10.00$, and a rain casing for a bike helmet costs around $€ 2.00$.

Instruments.

In the following, the instruments are described.

Pretest: Assessment of prior topic knowledge. A pretest containing 6 problems examined the prior knowledge of the participants. Intra-mathematical problems and problems addressing transitions were presented. Each problem was awarded with a maximum of 1 point; thus, the maximum score for the pretest was 6 points. To control for prior domain knowledge in mathematics, the participants were asked to report their last school grade in mathematics. 
Questionnaire: Subjective assessment. After the learning phase, the participants were asked to answer the questionnaire items "I knew exactly what to do", and "I found these problems easy" on a 4-stage rating-scale (1 indicating "yes" and 4 indicating "no").

Post-test: Assessment of learning outcomes. The post-test tested several aspects: four problems required the learners to find a translation between reality and mathematics ("translation"); one problem required them to solve an equation system ("intra-mathematics"); one problem required them to solve a modeling problem ("modeling"). Each post-test problem was awarded with a maximum of 1 point (partial credit for partially correct answers); thus, the maximum scores for the post-test categories were: 4 points for "translation", 1 point for "intra-mathematics", and 1 point for "modeling".

\section{Procedure.}

First, the participants worked on the pretest, which was followed by the learning phase (presentation of four problems), where the experimental variation took place. After the subjective assessment, they worked on the post-test. Finally, the learners were asked to report age, gender, and their last mathematics grade. The individual learning time and time for working on the tests was kept constant; the duration of the experiment was approximately 45 minutes.

\section{Results}

With respect to the pretest, the experimental groups did not differ significantly, $F(3,139)=1.08, p=$ .358. There were no significant group differences with respect to the mathematics grades, $F(3,137)=$ $1.15, p=.333$; two participants did not report their last mathematics grade. Thus, the participants in all conditions had about the same prior topic knowledge and prior domain knowledge. In order to have a comprehensive measure of prior knowledge in mathematics, the two measures of prior knowledge which correlated significantly, $r=-.34, p<.001$ - were combined to one score. In Germany, the grades range from 1 to 6, 1 indicating very good achievement and 6 indicating very poor achievement; thus, in order to account for this "wrong direction", the grades were reversed before they entered the combined score. The $z$-scores of the prior topic knowledge and the $z$-scores of the prior domain knowledge were added, and this sum was again $z$-standardized (with respect to the two participants who did not provide their mathematics grade, only the prior topic knowledge score entered the analyses). With respect to this combined prior knowledge measure, the experimental groups did not differ significantly, $F(3,139)=1.41, p=.242$. Table 3 shows the means (and standard deviations) of the prior knowledge and post-test scores in the experimental groups. No heterogeneous slopes from the post-test measures to the combined prior knowledge score were found, thus, the combined prior knowledge score entered GLM models as a continuous covariate. The analyses were computed as one-factorial analyses of variance, with "condition" as independent variable and the combined prior knowledge score as covariate.

Table 3: Means and standard deviations (in parentheses) of the prior knowledge scores ("pretest" and "combined prior knowledge") and post-test scores ("translation", "intra-mathematics", "modeling").

\begin{tabular}{lccccc}
\hline & $\begin{array}{c}\text { Pretest } \\
(\max : 6)\end{array}$ & $\begin{array}{c}\text { Combined prior } \\
\text { knowledge }\end{array}$ & $\begin{array}{c}\text { Translation } \\
(\max : 4)\end{array}$ & $\begin{array}{c}\text { Intra-mathe- } \\
\text { matics } \\
(\max : 1)\end{array}$ & $\begin{array}{c}\text { Modeling } \\
(\max : 1)\end{array}$ \\
\hline Forward fading & $2.55(1.41)$ & $-.01(1.02)$ & $1.57(.86)$ & $.51(.41)$ & $.24(.29)$ \\
Backward fading & $2.42(1.09)$ & $-.27(.86)$ & $1.34(.75)$ & $.66(.41)$ & $.21(.26)$ \\
Example-problem-pairs & $2.87(1.30)$ & $.19(1.09)$ & $2.00(.94)$ & $.64(.38)$ & $.22(.29)$ \\
Problem-example-pairs & $2.84(1.20)$ & $.08(.99)$ & $1.50(.85)$ & $.54(.42)$ & $.22(.30)$ \\
\hline
\end{tabular}

"Translation". With respect to the post-test category "translation", the main effect "condition" reached the level of significance, $F(3,138)=2.93, p=.036$, partial $\eta^{2}=.060$, medium effect. As expected, the influence of the combined prior knowledge score was significant, $F(1,138)=19.93, p<.001$, partial $\eta^{2}=$ .126, medium effect. Contrasting the groups "with fading" with the groups "without fading" did not 
yield a significant result, $F(1,138)=2.34, p=.129$. As Table 3 displays, the results of "forward fading" and "backward fading" were close together (and according to a simple effects test, this difference was not significant, $p=.432$ ). In contrast, "example-problem-pairs" were considerably more effective than "problem-example-pairs", and according to a simple effects test, this difference was actually significant, $p=.015$. The "example-problem pairs" condition yielded the best results, and actually significantly better compared to the "backward fading" condition, $p=.009$, and just barely not significantly better than the "forward fading" condition, $p=.056$. The "problem-example pairs" condition did not differ significantly from both fading conditions, $p=.590$ with respect to the "forward fading" condition, and $p=.802$ with respect to the "backward fading condition".

"Intra-mathematics". With respect to the post-test category "intra-mathematics", the influence of the combined prior knowledge score was significant, $F(1,138)=10.03, p=.002$, partial $\eta^{2}=.068$, medium effect. Descriptively, the "backward fading" condition yielded the best result, closely followed by the "example-problem pairs" condition. The "problem-example pairs" condition scored considerably lower. The lowest score was achieved in the "forward fading" condition. The main effect "condition" did not reach the level of significance, $F(3,138)=1.69, p=.173$. Contrasting the conditions "with fading" with the conditions "without fading" also did not yield a significant result, $F(1,138)=.117, p=$ .733. However, the superiority of "backward fading" over "forward fading" reached the level of significance, $p=.047$.

"Modeling". With respect to the most challenging problem of the post-test, no significant main effect "condition" was obtained, $F(3,138)=.20, p=.897$. Descriptively, the results are very close to each other; accordingly, the groups "with fading" and the groups "without fading" did not differ significantly, $F(1,138)=.57, p=.452$. The "backward fading" and the "forward fading" conditions did not differ significantly, $p=.965$, and no significant difference between "problem-example pairs" and "example-problem pairs" were found, $p=.866$. The combined prior knowledge score significantly influenced the modeling performance, $F(1,138)=24.27, p<.001$, partial $\eta^{2}=.150$, large effect.

In addition to objective learning outcomes, subjective statements of the learners were assessed as well. The learners rated statements expressing their own opinion on a four-stage rating scale (1 indicating "yes" and 4 indicating "no").

"I knew exactly what to do." With respect to this statement, the main effect "condition" just barely missed the level of significance, $F(3,135)=2.20, p=.091$, partial $\eta^{2}=.047$, small effect. The "exampleproblem pairs" group indicated the highest degree of certainty $(M=2.18, S D=.95,2$ missing values), followed by "forward fading" $(M=2.35, S D=.92)$ and "backward fading" $(M=2.37, S D=.91)$; the "problem-example pairs" group reached the lowest degree of certainty $(M=2.69, S D=.76,1$ missing value). Contrasting the groups "with fading" and the groups "without fading" did not lead to a significant result, $F(1,135)=1.12, p=.291$. The differences between the "example-problem pairs" group and the fading groups were both not significant according to a simple effects test, $p=.589$ with respect to "forward fading", and $p=.790$ compared with the "backward fading" group. The two fading groups did not differ significantly, $p=.786$. Whereas the difference between the "forward fading" group and the "problem-example pairs" group just barely missed the level of significance, $p=$ .072, both the "backward fading" group and the "example-problem pairs" group differed significantly from the "problem-example pairs" group, $p=.043$ and $p=.023$, respectively. The influence of the combined prior knowledge score was significant, $F(3,135)=14.58, p<.001$, partial $\eta^{2}=$ .097, medium effect. A negative correlation $(r=-.303, p<.001)$ between the item score and the combined prior knowledge score displays that learners with more prior knowledge declared more often to know exactly what to do than learners with less prior knowledge. The item also correlated negatively with the three post-test measures, $r=-.142, p=.095$ with "translation", $r=-.232, p=.006$ with "intra-mathematics", and $r=-.314, p<.001$ with "modeling", respectively. 
"I found these problems easy." With respect to this item, the participants in the "forward fading" ( $M=$ $2.41, S D=.78,3$ missing values) and in the "backward fading" ( $M=2.44, S D=.79,1$ missing values) conditions indicated that they found the problems easier than the participants in the "exampleproblem pairs" condition ( $M=2.53, S D=.79,1$ missing values), who in turn found them easier than the participants in the "problem-example pairs" condition $(M=2.79, S D=.78,3$ missing values). The main effect "condition" just barely missed the level of significance, $F(3,130)=2.47, p=.065$, partial $\eta^{2}=$ .054, small effect. Contrasting the conditions "with fading" with the conditions "without fading" led to a significant result, $F(1,130)=5.94, p=.016$, partial $\eta^{2}=.044$, small effect. According to a simple effects test, the two fading conditions did not differ significantly, $p=.900$, and the difference to the "example-problem pairs" condition also did not reach the level of significance, $p=.288$ for the "forward fading" condition and $p=.239$ for the "backward fading" condition, respectively. In contrast, both fading groups differed significantly from the "problem-example pairs" group, $p=.024$ for the "forward fading" group and $p=.018$ for the "backward fading" group, respectively. The difference between the "example-problem pairs" condition and the "problem-example pairs" condition did not reach the level of significance, $p=.227$. The influence of the combined prior knowledge score was significant, $F(1,130)=18.73, p<.001$, partial $\eta^{2}=.126$, medium effect. Again, a negative correlation between the combined prior knowledge and the item score $(r=-.329, p<.001)$ indicates that learners with better prior knowledge ranked the problems as more easy. The item also correlated negatively with the three post-test measures, $r=-.254, p=.003$ with "translation", $r=-.224$, $p=.009$ with "intra-mathematics", and $r=-.411, p<.001$ with "modeling", respectively.

\section{Discussion}

With respect to translation competencies, learning with example-problem pairs was most effective. No advantage of a fading procedure compared to alternately presenting examples and problems emerged, and both fading conditions were equally effective. However, learning with exampleproblem-pairs was significantly more effective than learning with problem-example-pairs. The example-problem pairs condition was also considerably more effective than the fading conditions (significantly in the case of backward fading, and just barely not significantly in the case of forward fading). Thus, if a fading procedure is used, it is largely irrelevant whether a forward or a backward rationale is implemented. However, in case of pairs of examples and problems, starting the sequence with an example is considerably more effective than starting with a problem and being presented an example only afterwards.

It has to be acknowledged that the learning materials posed very high demands on the learners by combining intra-mathematical and translation requirements, resulting in high element interactivity. If intrinsic cognitive load is high, the worked example effect - and other cognitive load effects - can be obtained (Sweller 2010); in this sense, cognitive load theory provides an explanation for the effectivity of example-problem sequences in the present study. Whereas the studies by Atkinson et al. (2003) and Renkl et al. $(2002,2004)$ found a superiority of backward fading compared to example-problem pairs, the present study did not reveal this effect clearly. Again, the very high element interactivity of the present learning materials might explain this effect.

Concerning intra-mathematical skills, no superiority of fading procedures over sequences of examples and problems could be shown. In case of using pairs of problems and examples, it did not play an important role whether these sequences started with examples or with problems. However, the "backward fading" condition outperformed the "forward fading" condition significantly; this result is in line with the findings of Renkl et al. (2002). This means that intra-mathematical skills were acquired better when the learners were required to complement solution steps from back to front. Possibly, it is easier for learners to complement a solution which at least presents the beginning than to find the first steps on their own. This may have reduced cognitive load, which, in turn, may have 
supported the acquisition of intra-mathematical skills. Following the argumentation of Renkl et al. (2002), it might be especially effective to fade out the easiest step first, as this reduces problem solving requirements and frees cognitive resources for effective learning activities. According to Verschaffel et al. (2010), considerations with respect to real aspects are especially rare when they refer to the translation from reality to mathematics; thus, it can be assumed that the last interpretation step is considerably easier than the first translation step. Thus, in the present context, fading out the easiest step first would mean fading out the last step first. This, in turn, is another explanation for the superiority of the "backward fading" condition.

With respect to the modeling problem in the post-test, no significant results were obtained. The solution rates were low in all groups, indicating that this problem was very challenging. Due to restrictions of the participating school, it was only possible to use a very short learning time. Further studies should assess whether significant group differences could emerge with respect to easier modeling problems, or by way of a prolonged learning time.

Concerning practical implications, subjective evaluations are very important. The item "I knew exactly what to do" correlated negatively with prior knowledge and with the post-test scores. This displays that knowing what to do goes hand in hand with being able to actually solve problems. The results show that beginning the learning sequence with an example - which means presenting a clear instantiation for what the learners are expected to do - fosters the learners' certainty what to do to a considerable extent, regardless whether this example is then followed by faded examples or by a problem to be solved.

The aspect of self-efficacy was also addressed by the item "I found these problems easy". Again, negative correlations with prior knowledge and post-test scores resulted, indicating that learners with better competencies rank the problems as more easy. The "problem-example pairs" learners found the problems the most difficult, which indicates that being required to solve a problem without having seen an example first is perceived especially difficult. In the groups with fading, the learners found the problems easier than in the groups without fading; thus, fading procedures - regardless of their direction - lower the perceived difficulty of the problems. This is relevant especially with respect to practice, where confidence and self-efficacy are of major importance.

Conclusions with respect to practical aspects.

The differences between the two fading conditions are rather small, and a significant difference only appears with respect to intra-mathematical competencies; there, the "backward fading" condition outperformed the "forward fading" condition. It should be noted that the backward rationale is also easier to implement: in this case, it suffices to present the learners a problem along with the first solution step(s) and to tell them to finish this solution. In contrast, a forward rationale implies that after presenting the problem formulation, the learners are asked to find the first solution step(s) on their own, and the last solution step(s) are then presented. Now, in this case, it is possible that the presented solution end does not match the self-generated solution approach of the student - which becomes a serious problem if multiple solution methods are possible and desired (e.g., Große 2014b; Große \& Renkl 2006; Star \& Rittle-Johnson 2008, 2009). Implementing a backward rationale circumvents this problem.

If sequences of examples and problems are implemented, the results show that translation skills are significantly better supported by starting with examples than by starting with problems. Apparently, worked examples which provide orientation and guidance are very helpful in the beginning of the learning process. 
With respect to real mathematics education, subjective evaluations are very important. Fading procedures - with the affordance of solving only one "new" step at a time - lower the subjective difficulty of the problems. As this fosters confidence and self-efficacy of the learners, this aspect should be focused in mathematics education.

In sum, it can be concluded that depending on the concrete outcome variable - covering objective and subjective aspects - approaches with (backward) fading procedures or example-problem pairs are especially effective. As they foster objective success and subjective opinions, these measures should especially be recommended for implementation in practice.

\section{Acknowledgements}

This work was supported by the German Research Foundation (DFG) under contract number GR2706/4-1 and by the Central Research Development Fund (CRDF) of the University of Bremen. The author would like to thank these institutions for their support. And many thanks go to Bàra W. Grollius for her assistance.

\section{References}

Atkinson, R. K., Derry, S. J., Renkl, A., and Wortham, D., (2000). Learning from examples: Instructional principles from the worked examples research. Review of educational research, 70, 181-214.

Atkinson, R. K., Renkl, A., and Merrill, M. M., (2003). Transitioning from studying examples to solving problems: effects of selfexplanation prompts and fading worked-out steps. Journal of Educational Psychology, 95, 774-783. doi: 10.1037/00220663.95.4.774.

Bandura, A., (1977). Self-efficacy: Toward a unifying theory of behavioral change. Psychological Review, 84, 191-215.

Bandura, A. and Locke, E. A., (2003). Negative self-efficacy and goal effects revisited. Journal of Applied Psychology, 88, 87-99. doi: 10.1037/0021-9010.88.1.87.

Blum, W., (1991). Applications and modelling in mathematics teaching - A review of arguments and instructional aspects. In M. Niss, W. Blum \& I. Huntley (Eds.), Teaching of mathematical modelling and applications (pp. 10-29). New York: E. Horwood.

Blum, W. and Borromeo Ferri, R., (2009). Mathematical modelling: Can it be taught and learnt? Journal of Mathematical Modelling and Application, 1, 45-58.

Borromeo Ferri, R., (2009). Zur Entwicklung des Verständnisses von Modellierung bei Studierenden [On the development of students' understanding of modeling]. In M. Neubrand (Ed.), Beiträge zum Mathematikunterricht 2009 (pp. 139-142). Münster: WTM.

Cooper, G. and Sweller, J., (1987). Effects of schema acquisition and rule automation on mathematical problem-solving transfer. Journal of Educational Psychology, 79, 347-362. doi: 10.1037/0022-0663.79.4.347.

De Kock, W. D. and Harskamp, E. G., (2014). Can teachers in primary education implement a metacognitive computer programme for word problem solving in their mathematics classes? Educational Research and Evaluation, 20, 231-250.

Galbraith, P. L. and Clatworthy, N. J., (1990). Beyond standard models - Meeting the challenge of modelling. Educational Studies in Mathematics, 21, 137-163.

Greer, B., (1997). Modelling reality in mathematics classrooms: The case of word problems. Learning and Instruction, 7, $293-307$.

Große, C. S., (2014a). Learning to solve story problems - Supporting transitions between reality and mathematics. European Journal of Psychology of Education, 29, 619-634. doi: 10.1007/s10212-014-0217-6.

Große, C. S., (2014b). Mathematics learning with multiple solution methods: effects of types of solutions and learners' activity. Instructional Science, 42, 715-745. doi: 10.1007/s11251-014-9312-y.

Große, C. S. and Renkl, A., (2006). Effects of multiple solution methods in mathematics learning. Learning and Instruction, 16, 122-138. doi: 10.1016/j.learninstruc.2006.02.001.

Kissane, M., Kalyuga, S., Chandler, P., and Sweller, J., (2008). The consequences of fading instructional guidance on delayed performance: The case of financial services training. Educational Psychology, 28, 809-822. doi: $10.1080 / 01443410802322069$.

Leiss, D., Schukajlow, S., Blum, W., Messner, R., and Pekrun, R., (2010). The role of the situation model in mathematical modelling - task analyses, student competencies, and teacher interventions. Journal für Mathematik-Didaktik, 31, 119-141. doi 10.1007/s13138-010-0006-y

Mevarech, Z. R., Terkieltaub, S., Vinberger, T., and Nevet, V., (2010). The effects of meta-cognitive instruction on third and sixth graders solving word problems. ZDM Mathematics Education, 42, 195-203. doi: 10.1007/s11858-010-0244-y.

Moreno, R., Reisslein, M., and Ozogul, G., (2009). Optimizing worked-example instruction in electrical engineering: The role of fading and feedback during problem-solving practice. Journal of Engineering Education, 98, 83-92. doi: 10.1002/j.21689830.2009.tb01007.x 
OECD (2003). The PISA 2003 assessment framework - Mathematics, reading, science and problem solving knowledge and skills. Paris: OECD.

Paas, F., Renkl, A., and Sweller, J., (2003). Cognitive load theory and instructional design: Recent developments. Educational Psychologist, 38, 1-4.

Palm, T., (2008). Impact of authenticity on sense making in word problem solving. Educational Studies in Mathematics, 67, 37-58. doi: 10.1007/s10649-007-9083-3.

Powell, S. R., (2011). Solving word problems using schemas: A review of the literature. Learning Disabilities Research E Practice, 26, 94-108.

Reinmann, G. and Mandl, H., (2006). Unterrichten und Lernumgebungen gestalten [Teaching and designing learning environments]. In A. Krapp \& B. Weidenmann (Ed.), Pädagogische Psychologie (pp. 613-658). Weinheim: Beltz PVU.

Reisslein, J., Atkinson, R. K., Seeling, P., \& Reisslein, M., (2006). Encountering the expertise reversal effect with a computerbased environment on electrical circuit analysis. Learning and Instruction, 16, 92-103. doi: 10.1016/j.learninstruc.2006.02.008.

Renkl, A., (2014). Toward an instructionally oriented theory of example-based learning. Cognitive science, 38, 1-37. doi: 10.1111/cogs.12086

Renkl, A., Atkinson, R. K., and Große, C. S., (2004). How fading worked solution steps works - A cognitive load perspective. Instructional Science, 32, 59-82.

Renkl, A., Atkinson, R. K., Maier, U. H., and Staley, R., (2002). From example study to problem solving: Smooth transitions help learning. Journal of Experimental Education, 70, 293-315. doi: 10.1080/00220970209599510.

Reusser, K. and Stebler, R., (1997). Every word problem has a solution - the social rationality of mathematical modeling in schools. Learning and Instruction, 7, 309-327.

Schukajlow, S. and Blum, W., (2011). Zum Einfluss der Klassengröße auf Modellierungskompetenz, Selbst- und Unterrichtswahrnehmungen von Schülern in selbständigkeitsorientierten Lehr-Lernformen [On the effect of class size on modeling competency and self-reported perceptions of students in self-regulated learning environments]. Journal für Mathematik-Didaktik, 32, 133-151. doi: 10.1007/s13138-011-0025-3.

Star, J. R. and Rittle-Johnson, B., (2008). Flexibility in problem solving: The case of equation solving. Learning and Instruction, 18, 565-579. doi: 10.1016/j.learninstruc.2007.09.018.

Star, J. R. and Rittle-Johnson, B., (2009). It pays to compare: An experimental study on computational estimation. Journal of Experimental Child Psychology, 102, 408-426. doi: 10.1016/j.jecp.2008.11.004.

Stark, R., (1999). Lernen mit Lösungsbeispielen. Der Einfluss unvollständiger Lösungsschritte auf Beispielelaboration, Motivation und Lernerfolg [Learning with worked examples. The impact of incomplete solution steps on example elaboration, motivation, and learning outcomes]. Göttingen: Hogrefe.

Sweller, J., (2010). Element Interactivity and Intrinsic, Extraneous, and Germane Cognitive Load. Educational Psychology Review, 22, 123-138. doi: 10.1007/s10648-010-9128-5.

Sweller, J. and Cooper, G. A., (1985). The use of worked examples as a substitute for problem solving in learning algebra. Cognition and Instruction, 2, 59-89. doi: 10.1207/s1532690xci0201_3.

Trafton, J. G. and Reiser, B. J., (1993). The contributions of studying examples and solving problems to skill acquisition. In M. Polson (Ed.), Proceedings of the $15^{\text {th }}$ Annual Conference of the Cognitive Science Society. Hillsdale, NJ: Erlbaum.

Van Gog, T., Paas, F., and van Merriënboer, J. J. G., (2004). Process-oriented worked examples: improving transfer performance through enhanced understanding. Instructional Science, 32, 83-98.

Van Gog, T., Paas, F., and van Merriënboer, J. J. G., (2006). Effects of process-oriented worked examples on troubleshooting transfer performance. Learning and Instruction, 16, 154-164. doi: 10.1016/j.learninstruc.2006.02.003.

Van Gog, T., Paas, F., and van Merriënboer, J. J. G., (2008). Effects of studying sequences of process-oriented and productoriented worked examples on troubleshooting transfer efficiency. Learning and Instruction, 18, 211-222. doi: 10.1016/j.learninstruc.2007.03.003.

Van Merriënboer, J. J. G., (1990). Strategies for programming instruction in high school: Program completion vs. program generation. Journal of Computing Research, 6, 265-285.

Verschaffel, L., De Corte, E., and Borghart, I., (1997). Pre-service teachers' conceptions and beliefs about the role of real-world knowledge in mathematical modelling of school word problems. Learning and Instruction, 7, 339-359.

Verschaffel, L., De Corte, E., and Lasure, S., (1994). Realistic considerations in mathematical modeling of school arithmetic word problems. Learning and Instruction, 4, 273-294.

Verschaffel, L., De Corte, E., and Vierstraete, H., (1999). Upper elementary school pupils' difficulties in modeling and solving nonstandard additive word problems involving ordinal numbers. Journal for Research in Mathematics Education, 30, 265285.

Verschaffel, L., Van Dooren, W., Greer, B., and Mukhopadhyay, S., (2010). Reconceptualising word problems as exercises in mathematical modelling. Journal für Mathematik-Didaktik, 31, 9-29. doi: 10.1007/s13138-010-0007-x.

Vilenius-Tuohimaa, P. M., Aunola, K., and Nurmi, J. E., (2008). The association between mathematical word problems and reading comprehension. Educational Psychology, 28, 409-426. doi: 10.1080/01443410701708228

Visser, J. and Keller, J. M., (1990). The clinical use of motivational messages: An inquiry into the validity of the ARCS model of motivational design. Instructional Science, 19, 467-500.

Zöttl, L., Ufer, S., and Reiss, K., (2010). Modelling with heuristic worked examples in the KOMMA learning environment. Journal für Mathematik-Didaktik, 31, 143-165. doi: 10.1007/s13138-010-0008-9. 